\title{
Um jogo educativo para compreensão de emoções em crianças autistas
}

\author{
Elisa Boff - Universidade de Caxias do Sul (eboff@ucs.br) \\ Claudia Danieli - Universidade de Caxias do Sul (claudia_danieli@yahoo.com.br)
}

\begin{abstract}
Resumo. Crianças com transtorno do espectro autista apresentam dificuldade de reconhecer e expressar emoções. Existem muitas pessoas com autismo e um número muito pequeno de aplicativos com o propósito de ajudá-los. Neste contexto, este artigo propõe o desenvolvimento de um software educativo mobile para auxiliar na compreensão das emoções em crianças autistas. Para chegar a solução proposta, foram realizados estudos de aplicativos que se assemelham ao proposto neste artigo, assim como estudos das principais tecnologias móveis. Em seguida, foi feita uma pesquisa com profissionais de educação especial para definição das características do aplicativo. Por fim, o aplicativo foi desenvolvido e disponibilizado para utilização e avaliação de profissionais de educação especial.
\end{abstract}

Palavras-chave: Software Educativo, Mobile, Autismo, Objeto de Aprendizagem

\section{AN EDUCATIONAL GAME FOR UNDERSTANDING EMOTIONS IN AUTISTIC CHILDREN}

\begin{abstract}
Autistics have difficulty in recognizing and expressing emotions. There are many people with autism and a very small number of applications in order to help them. In this context, this paper proposes the development of an mobile educational software to assist in the understanding of emotions in children with autism. To reach the proposed solution, studies of applications that resemble proposed in this paper, as well as studies of the major mobile technologies were performed. Then research was done with special education professionals to define the characteristics of the application. Finally, the application was developed and made available for use and evaluation of special education professionals.
\end{abstract}

Keywords: Educational Software, Mobile, Autism, Learning Objetcs

\section{Introdução}

Autismo é uma síndrome, portanto um conjunto de sintomas presentes desde o nascimento e que se manifesta invariavelmente antes dos três anos de idade. É caracterizado por respostas anormais a estímulos auditivos e/ou visuais e por problemas graves na compreensão da linguagem oral. A fala custa aparecer, e quando ocorre podemos observar a ecolalia (repetição de palavras), o uso inadequado de pronomes, estrutura gramatical imatura e grande inabilidade para usar termos abstratos (FACION, 2012).

De acordo com a $5^{\text {a }}$ edição do Manual Diagnóstico e Estatístico de Transtornos 
tendo incidência maior no sexo masculino, de 3 a cada 4 crianças com autismo. No Brasil, existem poucos estudos sobre o assunto, mas levando em consideração os dados da população do país divulgados pelo IBGE (IBGE, 2019) e cruzando com os dados estatísticos do transtorno em outros países, estima-se que no Brasil existam cerca de 630 mil pessoas abaixo dos vinte anos com esse transtorno.

As pessoas com autismo têm uma grande dificuldade de desenvolver relacionamentos interpessoais, pois não se interessam pelas outras pessoas, dispensam o contato humano e apresentam também dificuldade no desenvolvimento de outras habilidades sociais, principalmente na linguagem verbal e na corpórea (gestos, mímicas, contato visual direto, expressão facial etc.) (FACION, 2012).

De acordo com a $10^{\text {a }}$ Classificação Internacional de Doenças (CID-10) de 2007, o autismo é considerado como um Transtorno Global do Desenvolvimento, onde estaria presente um padrão de desenvolvimento anormal ou alterado, manifestado antes dos três anos de idade. $\mathrm{O}$ funcionamento anormal das habilidades da criança estaria relacionado a três áreas: interação social, comunicação e comportamento restrito e repetitivo. Essa tríade representa uma visão mais abrangente do espectro autista e forma a base para os critérios diagnósticos atuais, como descrito na $5^{\mathrm{a}}$ edição do Manual Diagnóstico e Estatístico de Transtornos Mentais (DSM-5). Os critérios do DSM-5 e da CID-10 podem ser resumidos como prejuízos qualitativos de interação social, prejuízos qualitativos na comunicação e padrões restritos e repetitivos de comportamento, interesses e atividades.

Segundo Cunha (2010), os computadores são considerados ferramentas promissoras para auxiliar o desenvolvimento de pessoas com autismo. Algumas das primeiras pesquisas que mostraram resultados positivos no uso do computador para tratar pessoas com autismo datam de 1973. Segundo Dautenhahn (2000, apud CUNHA, 2010), um dos principais fatores que motivam o uso de computadores no tratamento dessas pessoas é que por meio deles é possível criar ambientes controlados, interessantes e sem distrações. Essas são consideradas características importantes para o sucesso no tratamento de pessoas com autismo. Por esse motivo foi escolhido o uso de dispositivos móveis, que por não possuírem mouse nem teclado e o contato ser direto na tela, se torna mais interessante e diminui a distração dos autistas.

Autistas tem dificuldades para lidar com as suas emoções, não sabem como expressar o seu afeto e também não percebem a emoção ou os sentimentos dos outros. Em muitos casos não conseguem manter um contato olho a olho (CAMARGOS, 2002).

Para suprir essas necessidades, esse artigo apresenta o desenvolvimento de um aplicativo para dispositivos móveis com atividades específicas para autistas verbais. Como existem muitas áreas em que os autistas podem ter dificuldades, como já foi mencionado acima, o foco definido para este trabalho são atividades para melhorar a capacidade de comunicação e compreensão da relação entre situação e emoção.

As próximas seções apresentam um levantamento de trabalhos relacionados, uma revisão sobre as tecnologias para desenvolvimento móvel, a proposta de solução para o aplicativo de reconhecimento de emoções e as considerações finais.

\section{Trabalhos Relacionados}


autistas, e dentre os existentes a maioria é em inglês ou espanhol. Por causa disso, muitos pais e profissionais de educação especial acabam utilizando aplicativos que não foram criados pensando nas características e limitações da criança autista, o que muitas vezes dificulta e diminui as possibilidades de aprendizagem.

O Aiello (AIELLO, 2019) é um jogo online e gratuito desenvolvido especificamente para crianças autistas para aquisição e ampliação de vocabulário. O jogo é desktop o que pode dificultar o uso pelas crianças autistas devido à necessidade de usar o mouse. Segundo Correia (2006), portadores do espectro autista possuem uma coordenação motora consideravelmente abaixo da população dita normal. Por esse motivo, o uso de dispositivos móveis é mais indicado para autistas, pois o contato é diretamente na tela.

O Aprendendo Adjetivos (EARS, 2019) é um aplicativo comercial desenvolvido para iPhone e iPad pela empresa Smarty Ears, fundada pela fonoaudióloga brasileira Bárbara Fernandes e foi lançado em 2012. Foi desenvolvido para crianças com distúrbios de comunicação, de linguagem ou de desenvolvimento como crianças com autismo ou síndrome de down, entre outras síndromes. O aplicativo é indicado para pais, professores, educadores especiais ou fonoaudiólogos. Os adjetivos foram divididos em oito categorias (aparência, cores, sentimento, quantidade, formato, tamanho, temporal e tato), para que o ensino possa ser focado em uma área específica.

O aplicativo Fala Fácil Autismo (LABS, 2019) é voltado para autistas não verbais e está disponível para dispositivos móveis com o sistema operacional Android. Possui três botões com as opções "Eu quero", "Eu estou" e "Eu vou". Dependendo da opção escolhida, aparecem imagens abaixo do botão para o autista demonstrar o que deseja fazer. Por exemplo, escolhe o botão "Eu estou" e depois seleciona a opção "Doente". É muito útil para as crianças que não falam, pois muitas vezes elas não conseguem pedir o que querem ou demonstrar o que estão sentindo.

O aplicativo gratuito Touch and Learn - Emotion (APPS, 2019), para plataforma iOS. Ele não foi desenvolvido para o público autista, mas pode ser usado, pois auxilia na compreensão das emoções. Muitos autistas têm dificuldades para entender e expressar as emoções, segundo Assumpção Jr. et al. (1999). Para os autores, "existe uma dificuldade da percepção das expressões faciais nas crianças autistas, o que interfere diretamente nos relacionamentos sociais (...). Assim, a ausência desta característica cognitiva específica dificultaria a compreensão dos próprios estados mentais, bem como o dos outros". Nesse sentido, o aplicativo pode contribuir para auxiliar nesse aprendizado. A criança autista consegue reconhecer os elementos que compõe uma expressão facial, mas não apresenta condições de, ao juntá-los, atribuir a esta um significado específico. O aplicativo é focado em ajudar as crianças a ler a linguagem corporal e entender as emoções através da expressão facial. Esta aprendizagem se dá através de fotos de crianças demonstrando diferentes emoções.

Para desktop, o software EDUCAUTISM (Andreis, 2018) possui uma proposta de interação com o usuário por meio de uma interface totalmente personalizável, de acordo com o perfil da criança. A personalização leva em consideração a sensibilidade da criança com as cores, imagens, sons e outros aspectos relevantes.

Após o levantamento e análise dos trabalhos relacionados, verificou-se que o 
especificamente o foco desse trabalho, que é a compreensão da relação entre situação e emoção, o número de aplicativos é muito pequeno para a demanda.

\section{Tecnologias para desenvolvimento de aplicações móveis}

Atualmente o mercado de dispositivos móveis é caracterizado por duas grandes plataformas: Android e iOS. Segundo uma pesquisa recente realizada pela IDC (IDC, 2019), o Android está em primeiro lugar em market share com $86,7 \%$ de participação no primeiro semestre de 2019. Em segundo lugar aparece o iOS com 13,3\% de market share. Os outros representam uma quantidade inexpressiva de market share e por esse motivo não foram estudados nesse trabalho.

Ainda segundo essa mesma pesquisa, no primeiro semestre de 2019 foram vendidos 1,375 bilhão de dispositivos móveis. Em comparação com o mesmo período do ano anterior, as vendas caíram 1,9\% em 2019, mas com uma perspectiva de crescimento de $1,4 \%$ para o segundo semestre.

Para o desenvolvimento do aplicativo que proposto neste trabalho foi escolhido o sistema operacional Android, em função de possuir um número amplamente maior de usuários que o iOS. Além disso, outras características foram levadas em consideração, a saber: facilidade de desenvolvimento, hardware necessário, ambiente de desenvolvimento, linguagem de programação e custo de distribuição.

\section{O jogo educativo proposto}

Considerando o estudo realizado na Seção 2, verificou-se que o número de aplicativos em português e específico para autistas é muito pequeno para a demanda. Percebe-se a necessidade de aplicativos com características que atendam as necessidades desse público alvo específico, o que é o objetivo principal deste trabalho.

A solução proposta para neste artigo é um aplicativo para dispositivos móveis (tablets) com sistema operacional Android, com quatro atividades diferentes para estimular a compreensão da relação entre situação e emoção. Essas atividades foram definidas através de entrevistas realizadas com profissionais da área de educação especial, sendo uma fonoaudióloga e uma psicóloga. Cabe ressaltar que ambas as profissionais possuem experiência com crianças com autismo e desenvolvem atividades na APAEs (Associação dos Pais e Amigos dos Excepcionais) atendendo crianças que possuem esse transtorno.

Estas profissionais foram entrevistadas a fim de elencar os requisitos necessários para o jogo proposto. Após a entrevista, foram definidas quatro atividades para o jogo, com níveis diferentes de dificuldade. Com isso, o jogo poderá ser usado com crianças de diferentes níveis de aprendizagem. Também tem a opção de configuração das emoções, para que, conforme a criança for evoluindo, seja possível adicionar mais emoções para ampliar sua aprendizagem.

Para esta primeira versão do jogo, foram desenvolvidas imagens representando quatro emoções. Com o apoio das profissionais de educação especial, foram escolhidas as emoções as quais os autistas têm dificuldade para compreender e expressar, a saber: 
acompanhamento de um adulto (pais ou educadores especiais) a fim de direcionar a aprendizagem.

O jogo foi desenvolvido na IDE Eclipse na linguagem de programação Java com o auxílio da ferramenta SDK e o plugin do Eclipse ADT. Os testes foram feitos em uma máquina virtual do Android e também em um tablet Samsung sete polegadas com o sistema operacional Android 4.0.

A primeira atividade proposta pelo aplicativo é o Reconhecimento de Emoções. A partir do momento em que a criança consegue jogar essa primeira atividade com facilidade ela pode jogar a segunda atividade e assim por diante. O objetivo dessa atividade é possibilitar à criança a identificação de emoções somente pela expressão dos rostos apresentada nas imagens. Para isso, o jogo mostra para a criança desenhos de pessoas com diferentes expressões faciais demonstrando alguma emoção e a criança deve escolher entre as opções qual emoção aquele desenho representa.

Essa primeira atividade não envolve nenhum tipo de situação para que a criança tenha que deduzir através do contexto essa emoção, é somente uma atividade para reconhecimento direto de emoções. Autistas têm essa dificuldade para expressar as suas emoções e reconhecer emoções nas outras pessoas conforme citado na Introdução deste artigo.

A Figura 1 apresenta a tela do aplicativo com a primeira atividade. Nessa interface, quando é clicado nos botões das emoções (feliz, triste, assustado e bravo), a mascote fala o nome dessas emoções, e em seguida apresenta o feedback do acerto ou do erro de acordo com a opção escolhida. Optou-se por usar esse modelo tradicional de feedback somente com um som característico de acerto ou erro, pelo fato de as crianças autistas terem muita dificuldade em entender uma frase. Isso foi uma recomendação das profissionais de educação especial. Segundo as especialistas, "atividades e/ou comandos para autistas devem ser simples e objetivos, deve-se usar sempre frases curtas" e, ainda, "as ordens dadas ao paciente devem ser curtas, com frases simples e objetivas".

No momento em que abre a atividade e também quando clica diretamente na mascote, ela vai faz a seguinte pergunta "Como o(a) menino(a) está se sentindo?".

As educadoras especiais também indicaram como deve ser o layout do aplicativo. A psicóloga frisa que "as imagens e as telas em geral não devem ser muito coloridas, nem com muitos estímulos visuais ou auditivos", e a fonoaudióloga corrobora indicando que se deve "evitar usar muitos distrativos na tela, como animações, por exemplo, que irão desviar a atenção da criança do objetivo proposto". Essa recomendação foi seguida e por esse motivo a interface é simples, limpa e tem somente o necessário para não tirar a atenção da criança. Também não tem muitas animações, a não ser no momento do acerto para estimular a criança. Os sons apresentados são apenas de palavras ou frases curtas que ajudam na compreensão, sempre ditos pela mascote. Também se teve o cuidado de fazer as animações com poucas cores e com movimentos lentos. 


CINTED-UFRGS Novas Tecnologias na Educação

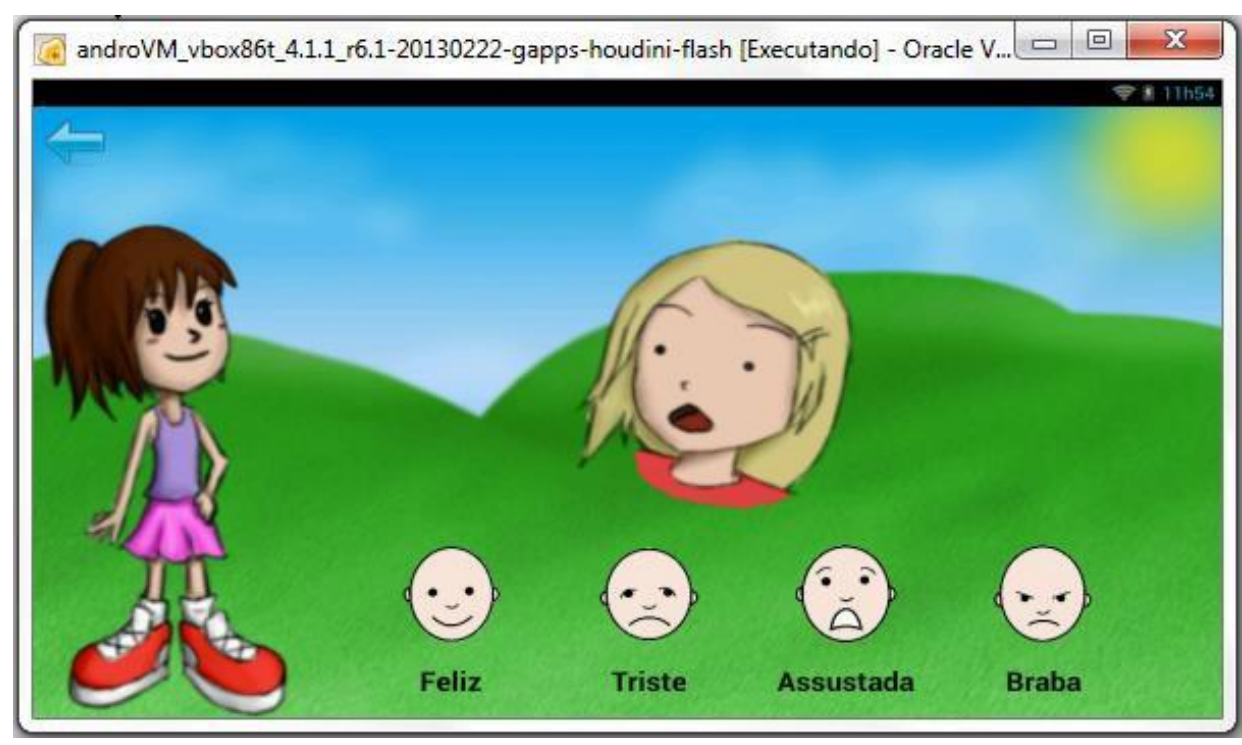

Figura 1 - Interface da Atividade de Reconhecer Emoções

A segunda atividade propõe um jogo de relacionar emoções em pares. O relacionamento dos pares de figuras é uma das atividades que é usada com autistas, conforme foi relatado pela fonoaudióloga. Segundo a especialista, nas APAEs os profissionais de educação especial aplicam este mesmo exercício com cartões de papel, em que cada cartão contém um desenho e as crianças precisam encontrar os dois cartões que formam o par.

Nesta atividade, o jogo propõe imagens iguais e também imagens diferentes, mas que representam a mesma emoção, para que a criança relacione os pares. Por exemplo: menina e menino feliz, menina e menino triste, adulto e criança feliz, adulto e criança triste, etc.

Além de relacionarem as emoções neste exercício, pode-se explorar com as crianças o conceito de igual e diferente.

A Figura 2 ilustra a interface da atividade Associar Emoções. Nessa atividade, quando a criança clica em uma das cartas da tela, a mascote fala o nome dessa emoção, para ajudar na fixação da palavra e no reconhecimento da emoção para a criança, como na atividade anterior. $\mathrm{O}$ feedback dado pelo acerto ou pelo erro segue a mesma lógica da primeira atividade. Quando a criança entra nessa atividade, ou quando clica na mascote, ela fala a seguinte frase "Encontre os pares".

Também é possível observar pela Figura 2, que o aplicativo está configurado para mostrar somente as emoções feliz, triste e assustado. A emoção bravo está desabilitada. A seleção das emoções que serão apresentadas a criança, pode ser feita pelo profissional ou adulto que acompanha o uso, e pode ser feita no ícone de engrenagem (porção superior direita da interface da Figura 2). Nestas configurações, é possível escolher entre os gêneros das imagens apresentadas (feminino e masculino). 


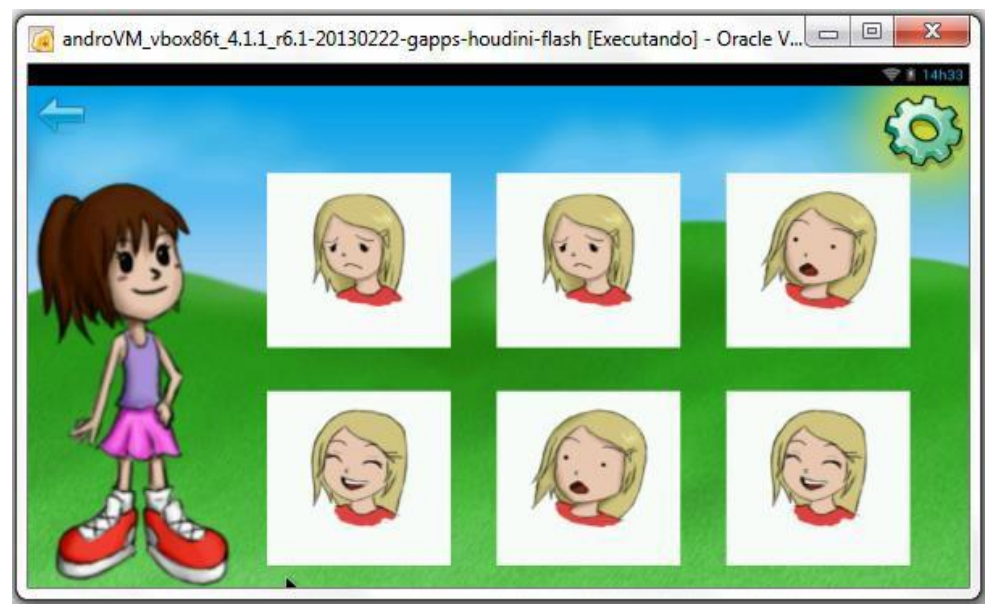

Figura 2 - Interface da Atividade de Associar Emoções

A atividade Contextualizar Emoções é visualmente muito parecida com a primeira atividade, a de Reconhecer Emoções. Nesta atividade, porém, sempre há uma situação, um contexto, envolvendo a emoção. Ela tem o objetivo que a criança consiga compreender uma emoção através da interpretação de determinada situação, ou seja, pela interpretação do contexto da imagem. Isso é muito importante para que a criança consiga fazer o mesmo no seu cotidiano, interpretando uma situação e a emoção que ela gera para o próximo, e também para si mesma.

Essa atividade possui uma mecânica parecida a da primeira atividade. Nesta, porém, a cada vez que muda a imagem, a menina mascote fala uma nova frase. Como no exemplo da Figura 3, onde ela diz "O menino ganhou um presente, então ele está...".

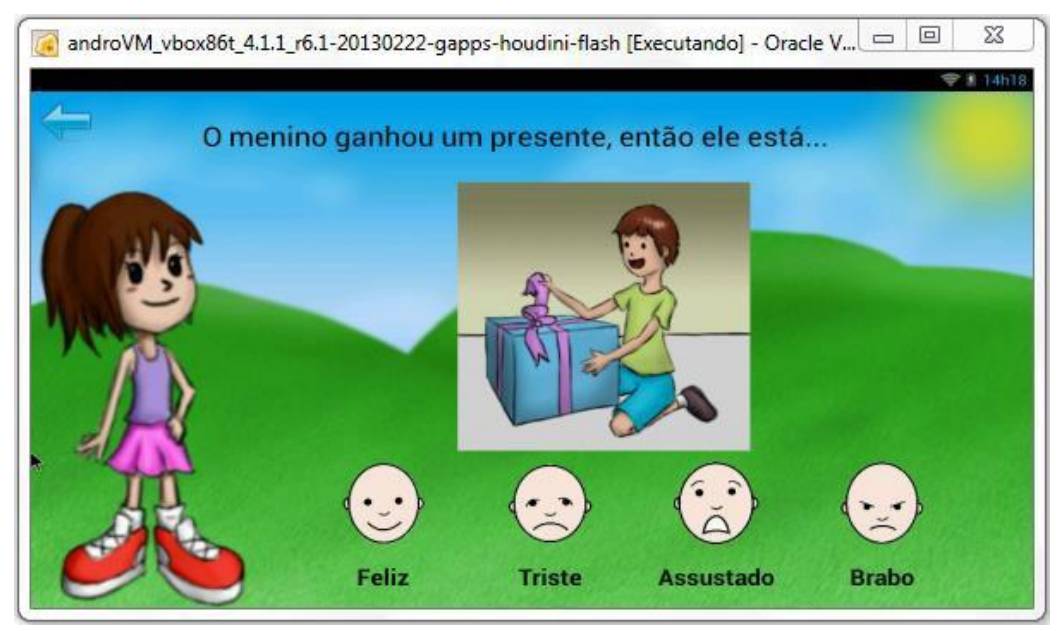

Figura 3 - Interface da Atividade de Associar Emoções

A atividade Sequenciar Emoções é a última e mais complexa das atividades. Ela exige que a criança consiga reconhecer as emoções através da interpretação das imagens, conhecimento esse que foi estimulado nas atividades anteriores. 


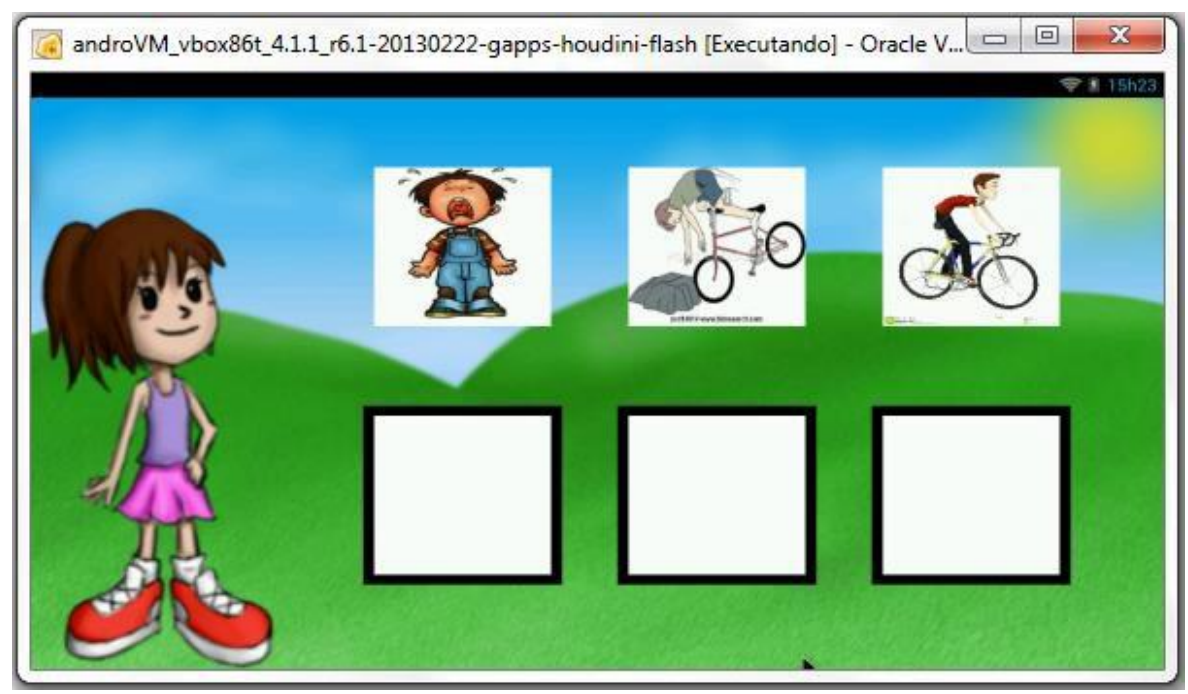

Figura 4 - Interface da Atividade de Sequenciar Emoções

O jogo mostra imagens em ordem aleatória que juntas formam uma situação que desencadeia uma emoção. A criança deve colocar essas imagens numa sequência lógica de acontecimento. $\mathrm{O}$ objetivo dessa atividade é que a criança consiga entender a causa e o efeito de uma situação, para assim poder ordenar as imagens e compreender determinada emoção. Segundo as especialistas que apoiaram no desenvolvimento deste trabalho, "os autistas tem dificuldades também em organização e sequência das atividades", e ainda completam dizendo que uma das atividades que são realizadas é de "colocar numa sequência lógica as imagens que representam atividades do dia a dia".

A Figura 4 ilustra a interface da atividade de Sequenciar Emoções. Quando a criança seleciona esta atividade, ou quando clica na mascote, ela fala a seguinte frase "Coloque as imagens na ordem correta". Quando a criança clica em uma das imagens da tela, a mascote fala a descrição dessa imagem. Na situação apresentada na Figura 4, a mascote diz: "O menino está chorando", "O menino caiu da bicicleta" e "O menino está andando de bicicleta". Quando a criança acerta a sequência, a mascote fala a frase completa, por exemplo: "O menino estava andando de bicicleta, caiu e está chorando".

Além das quatro atividades propostas às crianças, existe a possibilidade de Configurar Emoções, personalizando todas as atividades propostas pelo jogo. Para isso, o especialista ou responsável que acompanha o uso do jogo pode indicar as emoções que deseja que apareçam em todas as quatro atividades. Com isso, ele pode selecionar de uma a quatro emoções, e são estas que serão exploradas nas atividades escolhidas. A medida que a criança precisa de novos estímulos, poderão ser selecionadas mais emoções.

\section{Validação e Resultados}

Para validar a proposta, testes com pacientes foram conduzidos com o apoio das especialistas que acompanharam este trabalho. A fonoaudióloga utilizou o jogo com duas crianças autistas durante quatro semanas em duas sessões semanais com cada criança. Os dois pacientes eram meninos, um de quatro e outro de sete anos. Ela informou que para ambas as crianças "a aceitação e interesse foram imediatos". Apesar do curto período de tempo de utilização do jogo, segundo ela ambas as crianças 
progrediram no aprendizado das emoções propostas no jogo.

Por meio de entrevista, a mãe da criança de 7 anos declarou que seu filho passou a utilizar em casa mais as expressões exploradas no aplicativo. Apesar da primeira atividade (Reconhecer Emoções) ser a atividade menos complexa, as duas crianças tiveram mais facilidade na segunda (Associar Emoções) e na terceira atividade (Contextualizar Emoções), do que na primeira. Isso se deve ao fato do autista ter dificuldade de olhar um rosto como um todo, visto que fixavam o olhar na boca dos personagens e com isso faziam confusão com a emoção feliz e assustado, e também com a emoção triste e bravo, em que a boca dos personagens eram similares. Este resultado foi explicado pela fonoaudióloga: "Essa troca está relacionada ao comportamento que os autistas apresentam, de observar os detalhes e não o contexto geral e também que direcionam o olhar mais para a boca do que para a expressão facial".

A fonoaudióloga também utilizou o aplicativo com crianças de outras patologias como síndrome de down, deficiência auditiva e atraso na linguagem. E citou que "todos se interessaram e interagiram adequadamente com o software". Por fim, a profissional deu a sua avaliação final do aplicativo: "O aplicativo atingiu o objetivo, pois contemplou atividades relacionadas às emoções, seu reconhecimento, associação e contextualização, permitindo ao paciente refletir e melhor compreender esse aspecto do desenvolvimento". Um ponto positivo que foi destacado por ambas as profissionais foi o fato de o aplicativo permitir a escolha das emoções que serão trabalhadas.

\section{Considerações Finais}

Este artigo apresentou um estudo sobre softwares para apoiar o desenvolvimento de crianças autistas e propôs um jogo educativo para estimular o reconhecimento de emoções neste público-alvo. O jogo educativo foi modelado e implementado para dispositivos móveis (tablets) com sistema operacional Android. Durante o processo de desenvolvimento os pesquisadores contaram com o apoio de especialistas (uma psicóloga e uma fonoaudióloga) para concepção das funcionalidades do jogo.

As atividades propostas pelo jogo foram planejadas para crianças com características específicas, os autistas verbais. Crianças autistas podem apresentar dificuldades de desenvolver habilidades sociais. Por este motivo, foram selecionadas atividades que promovessem a melhora na capacidade de comunicação e compreensão da relação entre situação e emoção. Os resultados apresentados na seção 5 mostram que foi possível despertar o interesse das crianças e também estabelecer uma relação entre situações e emoções evocadas.

Como trabalho futuro está previsto o desenvolvimento de novas expressões faciais (emoções) e situações para a terceira e quarta atividades.

\section{Agradecimentos}

Agradecemos o apoio das especialistas no desenvolvimento deste trabalho: psicóloga Cristiane Rech Baal e fonoaudióloga Mirtes Adiles Sandri. 


\section{Referências}

AIELLO. Aiello Aquisição de Vocabulário, 2019. Disponível em: <http://www.jogoseducacionais.com/>. Acesso em fevereiro de 2019.

ANDREIS, Ivan e RIGO, Sandro José. EDUCAUTISM: Um sistema personalizável para o apoio à educação de criaças diagnosticadas com o transtorno do espectro autista. Revista Novas Tecnologias na Educação (RENOTE). 2018.

APPS, I. M. Touch and Learn - Emotions. 2013. Disponível em: <https://itunes.apple.com/br/app/touch-and-learn-emotions/id451685022?mt=8>. Acessado em fevereiro de 2019.

ASSUMPCAO JR, FRANCISCO B.; SPROVIERI, MARIA HELENA; KUCZYNSKI, EVELYN and FARINHA, VERA. Reconhecimento facial e autismo. Arq. NeuroPsiquiatr. [online]. 1999, vol.57, n.4, pp. 944-949. ISSN 0004-282X. Disponível em: <http://www.scielo.br/pdf/anp/v57n4/1160.pdf>. Acessado em março de 2019.

CAMARGOS, W. Transtornos Invasivos do Desenvolvimento $3^{\circ}$ Milênio. 1.ed. Brasília, 2002.

CORREIA, N. M. M.; Estudo Exploratório dos Níveis de Coordenação Motora em Indivíduos com Perturbações do Espectro Autismo, 2006. Disponível em: <http://repositorio-aberto.up.pt/bitstream/10216/13809/2/2901.pdf>. Acesso em Março de 2019.

CUNHA, R. M. Desenvolvimento e Avaliação de um Jogo de Computador para Ensino de Vocabulário para Crianças com Autismo. SBGAmes 2011. Disponível em: < http://www.sbgames.org/sbgames2011/proceedings/sbgames/papers/gamesforchange /SBGames-GamesForChange-

Desenvolvimento_e_Avaliacao_De_Um_Jogo_De_Computador_Para_Ensino_De_V ocabulario_Para_Criancas_Com_Autismo.pdf>. Acesso em abril de 2019.

DSM-5. Manual diagnóstico e estatístico de transtornos mentais [recurso eletrônico] : DSM-5 / [American Psychiatric Association; tradução: Maria Inês Corrêa Nascimento... et al.] ; revisão técnica: Aristides Volpato Cordioli ... [et al.]. - 5. ed. - Dados eletrônicos. - Porto Alegre: Artmed, 2014.

EARS, S. Aprendendo Adjetivos. Itunes. 2019. Disponível em: <http://www.ipadfono.com/aprendendo-adjetivos/>. Acesso em maio de 2019.

FACION, J. R. Transtornos do Desenvolvimento e do Comportamento. Belo Horizonte: Intersaberes-Ibpex, 2012.

IBGE, 2019. IBGE. Disponível em: <https://educa.ibge.gov.br/jovens/conheca-obrasil/populacao/20551-pessoas-com-deficiencia.html>. Acesso em maio de 2019.

IDC, 2019. Participação no mercado de smartphones. Disponível em: <https://www.idc.com/promo/smartphone-market-share/os>. Acesso em julho de 2019.

LABS, G. B. Fala Fácil Autismo. 2019. Disponível em <https://play.google.com/store/apps/details?id=com.benitez.DiegoDizPro>. Acesso em março de 2019. 